\title{
Future Exponential Economic Growth in Space
}

\author{
Harry W. Jones ${ }^{1}$ \\ NASA Ames Research Center, Moffett Field, CA, 94035-0001
}

\begin{abstract}
The human population and economy are now limited by the land area, materials and energy available on Earth. As explained by Malthus, human effort can increase this population limit only gradually and linearly at any fixed level of technology. The unexpected exponential increase in population since Malthus' time is due to the even greater exponential increase in agricultural and industrial productivity due to modern technology. Current opinion is divided between the limiters who see fast approaching unavoidable limits to growth and growthers who expect continuing innovation and expansion. Given the minimum energy and food needed to support each human, the population of Earth is necessarily bounded. The past human exponential expansions were based on the invention of agriculture and industry. Continued expansion could occur with future colonization of the solar system. The initial occupation of near-Earth space would probably be for immediate military and economic gains rather than to escape the limits to growth on Earth. Space habitats could exploit solar system energy, materials, and living space, first in the Earth-moon system and later throughout the solar system. Space habitats would be supported by robotic power stations, mining, manufacturing, and transportation. These could travel to the stars with the addition of propulsion and nuclear power. Human expansion into the galaxy would allow continuing exponential growth and could establish a vast interconnected galactic civilization.
\end{abstract}

\section{Nomenclature}

$\begin{array}{ll}a & =\text { Amount of linear growth } \\ c & =\text { The speed of light } \\ E & =\text { Efficiency of photosynthetic food production } \\ n & =\text { Number of generations } \\ N & =\text { Population } \\ r & =\text { Rate of exponential increase } \\ W & =\text { Watts, power }\end{array}$

\section{Introduction}

$\mathrm{T}$

HE human population and economy are limited by the energy, land area, and resources available on Earth. The nature, proximity, and inevitability of the limits to growth have been highly controversial. Limits alarmists have emphasized the rapid approach of clear unavoidable limits. Limits deniers point out that so far all past prophecies of doom have proved false. Something always turns up to produce more and faster growth. Locally and in the short term, here and now, growth continues without limit. Globally and in the far future, limits must take effect. The best ultimate hope for the human population and economy would then be a prosperous but restricted steady state. If continued growth is impossible, at least destructive collapse may be avoided. History is not encouraging. Many past complex civilizations have collapsed spectacularly and those often dissolve into simpler more primitive societies. Prophets of doom multiply. Should we merely hope for the inevitable to be postponed or can we find a way to escape the limits to growth?

\section{Malthus and linear versus exponential growth}

The limits to human population were first explained by Malthus in the late 1700's. Early economic growth was largely due to an increasing work force using more land and capital equipment. Malthus showed that there was a limit on population, assuming that food production technology would not improve. But since Malthus' time, the

\footnotetext{
${ }^{1}$ Systems Engineer, Bioengineering Branch, Mail Stop N239-8.
} 
productivity of labor and capital has increased greatly due to the advance of technology. Because human productivity has grown faster than population, both living standards and population have increased exponentially.

\section{A. Linear versus exponential growth}

Linear growth occurs when a variable increases by a constant amount added at the same rate over time. If the variable $\mathrm{x}_{\mathrm{t}}$ has the initial value $\mathrm{x}_{0}$ and grows linearly by the amount "a" per unit time, its value at time $\mathrm{t}$ is

$$
x_{t}=x_{0}+a t=x_{t-1}+a
$$

The increase from $x_{t-1}$ to $x_{t}$ is the constant amount "a". Suppose you put $\$ 100$ in the bank and it earns $5 \%$, or $\$ 5$ interest yearly. If you withdraw the $\$ 5$ earnings every year and put it under the mattress, you will have $\$ 350$ in 50 years, $\$ 100$ in the bank and $50 \times \$ 5=\$ 250$ under the mattress.

Exponential growth occurs when the increase in a variable is equal to its current value multiplied by a fixed growth rate. If the variable $x_{t}$ has the initial value $x_{0}$ and grows exponentially at the rate $r$, its value at time $t$ is

$$
\mathrm{x}_{\mathrm{t}}=\mathrm{x}_{0}(1+\mathrm{r})^{\mathrm{t}}=\mathrm{x}_{\mathrm{t}-1}(1+\mathrm{r})
$$

The increase from $x_{t-1}$ to $x_{t}$ is $x_{t-1} r$. Suppose you have $\$ 100$ that earns $5 \%$ and you leave the interest in the bank. In 50 years you will have $(1.05)^{50}=\$ 1,147$ in the bank. Over time, exponential growth vastly exceeds linear growth.

\section{B. Malthus' growth analysis}

Malthus observed that arable land and food production can increase no faster than linearly with time. He assumed that at best they could increase by the initial amount once every human generation. Food production then increases linearly. If $\mathrm{n}$ is the number of generations, the increase is

$$
1+1=2,2+1=3,3+1=4, \ldots, n+1
$$

Malthus also observed that the human population and need for food could increase exponentially, roughly doubling in each generation

$$
2^{1}=2,2^{2}=4,2^{3}=8, \ldots, 2^{\mathrm{n}}
$$

The ratio of the food produced divided by human population is the food available per person, which decreases with the number of generations, $n$, as

$$
2 / 2=1,3 / 4=0.75,4 / 8=0.5, \ldots,(n+1) / 2^{n} \sim 0 \text { for large } n .
$$

Clearly, if food increases linearly and population exponentially, the population will be limited by the food supply in a few generations. ${ }^{1}$

Malthus was correct in his math but wrong in his prediction because his key assumption proved false. He assumed that the material basis of life could improve only linearly, not exponentially as it has. He assumed that, without moral restraint, population would be controlled by famine and the resulting war and disease. Population increase has recently slowed, with absolute population declines expected in Japan and China, Russia and Europe. Since global living standards are increasing, this decline is not caused by lack of food.

Malthus' assumptions were inspired by his conservative, even reactionary philosophy. He first published his "Essay on Population" in the late 1700's, when the American and French revolutions were sweeping away old forms of government. Enlightenment thinkers such as Voltaire and Franklin expected reason, science, and technology to produce universal and perpetual peace and prosperity. Against this Enlightenment optimism, Rousseau argued that the advancement of science and technology produced no real progress but instead decadence and corruption of the noble savage.

Nevertheless, material progress cannot be denied and should not be disparaged. Now most of us, more every day, have better nutrition, health, comfort, social circumstances, and personal freedom than had Malthus or Rousseau, even though they were famous in their time. Their negative assumptions led to an erroneous prediction. On the other hand, conservatives seem correct that humans are not much improved, perhaps even made worse by modernism. 
Malthus' principle of population is true and fundamental in natural ecosystems, where it inspired Darwin's ideas of evolution and the struggle for existence.

What is surprising is that humanity, so far, has escaped the Malthusian population limit and controls that rule the rest of nature. Many thinkers, the limiters, expect and confidently predict that our current high technology civilization will soon reach a hard limit on food or oil and then quickly begin an irreversible decline. The limiters are correct when they say that nothing goes on forever, and that if something can't go on, it won't go on. The only unchanging stable state for a living organism or a dynamic system is inevitable death. Life consists of dynamic transitions and temporary stable states.

The limiters tend to use simple partial models pushed to the extremes, without feedback or adjustments. Until now, all predictions of a limit have failed. No hard limit is on the visible horizon. Limiters tend to shrink the timeline of future history and bring their predictions alarmingly forward into current lifetimes. They consider few options and alternatives, urging like Malthus their preferred remedies and ignoring or rejecting other paths to avoid disaster. To be clear, the limiters predict disaster to persuade others to implement their preferred solutions.

\section{Limits to growth}

The "Limits to Growth" was a well-publicized and controversial book published in 1972. Dynamic computer simulations were used to predict future levels of population, food production, industrialization, resource depletion, and pollution, assuming they grew exponentially and interacted. ${ }^{2}$

The report summary states that if the present growth trends continue, "the limits to growth on this planet will be reached sometime within the next one hundred years," probably resulting in sudden collapse. ${ }^{3}$ Overshoot and collapse is a standard dynamic system response. The first simulation collapsed because of resource depletion and the increasing capital required to access resources. Population then decreased because of a lack of food. The report summary observes that, "many people expect technological breakthrough to go on raising physical ceilings indefinitely." But even making "the most optimistic" assumptions, "The result is still an end to growth before the year 2100," due to overuse of land and failing food production, the original Malthusian limit. Significant effects were predicted by now. ${ }^{3}$

Real-world data from 1970 to 2000 nearly match the baseline 1972 predictions, but all the actual data curves show continuing exponential growth, with no flattening or incipient decline. Food per capita is slightly higher than predicted and pollution lower. ${ }^{4}$ The model's exponentially increasing global pollution with serious effects can be interpreted in hindsight as a prediction of global warming as the result of carbon dioxide accumulation in the atmosphere.

The Nobel prize winning economist Robert Solow observed, "“The authors load their case by letting some things grow exponentially and others not. Population, capital and pollution grow exponentially in all models, but technologies for expanding resources and controlling pollution are permitted to grow, if at all, only in discrete increments." In "Limits to Growth," as with Malthus, demands grow exponentially and resources only linearly. The assumptions determine the results, and philosophy and plans for the future influence the assumptions.

\section{A. No nuclear energy utopia}

The first and strongest of "the most optimistic" assumptions in Limits to Growth was "nuclear energy will solve the resource problems of the world," but still growth came to an end. ${ }^{3}$ Abbot considered whether nuclear power could be massively scaled in order to meet our global energy needs. He concluded that there are fundamental engineering and resource scaling limits that make a nuclear utopia impractical and that solar thermal farms would eliminate many nuclear power problems and could be scalable to deliver hundreds of terawatts in the future. The amount of solar power that reaches ground level is about ten thousand times the present world consumption. ${ }^{6}$

\section{B. Fundamental limits to growth}

What are the general factors that could limit the exponential growth of the human population and on Earth? The following fundamental limits have been suggested:

- Food production

- Energy resources

- Material resources

- Environmental quality

- Available space

Food production is the original Malthusian limit to population. Agriculture requires land, sun, water, and the appropriate climate. Modern farming adds machinery, fertilizers, herbicides, pesticides, and hybrid and genetically 
modified seeds. Food production could be limited by any of the other general factors; energy, material, environment, or available space. Fossil fuels, gas, oil, and coal, are clearly limited and being depleted. Nuclear energy is limited, but solar energy is constant and vastly exceeds current human use. Materials can become scarce and expensive. High grade metal ores can be depleted. The petroleum to produce plastics and synthetic fibers is becoming more costly. But materials can be recovered and reconstituted with sufficient energy. Environmental quality is being degraded, but this could be stopped or reversed with sufficient investment in alternative energy and counter measures. Space is required for human habitation, agriculture, industry, and solar energy capture. Farm land is limited but much space is empty or little used.

There are many potential limits to growth. If we escape one, we approach another. Earth is a closed system for matter, except for material from comets and meteors. Earth's materials, environmental air and water buffers, and surface area are strictly limited. But it is possible to imagine a much larger population living in many storied buildings constructed using the iron of Earth's core and supplied with recycled air and water. Material, environmental, and space limits may be avoided. Energy limits are a current concern. But after all fossil fuels are discovered and used, after all the uranium is expended, the Earth will still receive constant solar radiation for billions of years. Earth is an open system for energy. It receives sunlight during the day and radiates heat at night, maintaining on average a suitable temperature.

The ultimate long term limit to life on Earth is defined by solar energy. The maximum human population is that which Earth's solar energy can support. Other limits to growth may restrict the population to lower values, but the incident solar energy limit cannot be exceeded in the long run.

\section{The solar energy and photosynthetic food production limit}

The available solar energy, the efficiency of food production from sunlight, and the average human food energy requirement combine to limit the maximum population.

\section{A. How much solar energy does Earth receive?}

The total surface area of the earth is

$$
4 \pi \mathrm{r}^{2}=11.57 \times(6,371 \mathrm{~km})^{2}=5.101 \times 10^{8} \mathrm{~km}^{2}
$$

The solar energy is intercepted by a circular area facing the sun of

$$
\pi \mathrm{r}^{2}=3.14 \times(6,371 \mathrm{~km})^{2}=1.275 \times 10^{8} \mathrm{~km}^{2}
$$

The extraterrestrial solar radiation is 1,367 watts (W) per square meter, averaged over the year.

The total solar radiation energy intercepted by the Earth is

$$
1.275 \times 10^{8} \mathrm{~km}^{2} \times 10{ }^{6} \mathrm{~m}^{2} / \mathrm{km}^{2} \times 1,367 \mathrm{~W} / \mathrm{m}^{2}=1.742 \times 10^{17} \mathrm{~W}
$$

The current total worldwide energy consumption is about $1.5 \times 10^{13}$ watts, only about one part in 10,000 of the incident solar energy.

If there are seven billion people, each consumes about

$$
1.5 \times 10^{13} \mathrm{~W} / 7 \times 10^{9} \text { persons }=2.1 \times 10^{3} \mathrm{~W}=2,100 \mathrm{~W}
$$

\section{B. Food production energy efficiency}

Plants produce food and other biomass by photosynthesis, the production of glucose from carbon dioxide and water using light energy. The photosynthetic efficiency is the fraction of light energy converted into chemical energy in glucose. Only $45 \%$ of sun light is in photosynthetically active wavelengths. The theoretical maximum efficiency of solar energy conversion is approximately $11 \%$, but plants do not absorb all incoming sunlight and do not convert all they absorb into biomass, so the overall photosynthetic efficiency is only 3 to $6 \%{ }^{7}$

Biomass may be only $10 \%$ edible. Wheat has one of the highest harvest indexes since about half the biomass is edible grain. Feeding biomass to animals for meat production reduces the resulting food calories by roughly a factor 
of ten. Transportation and processing food may require several times as many calories as the food contains. Considering all these losses, photosynthetic efficiency, harvest index, conversion to animal products, and transportation and processing, the net calories consumed by humans are currently only about one part in ten thousand of the solar radiation energy received by food crops.

$$
0.03 \times 0.1 \times 0.1 \times 0.3=0.00009 \sim 10^{-4}
$$

To allow higher maximum populations, the efficiency of conversion from solar to food energy will be varied from efficiency $\mathrm{E}=10^{-4}$ up to $10^{-1}$, corresponding to the range from the approximate current value to the maximum theoretical efficiency.

\section{Human food energy requirement}

Human food energy must be converted from calories into watts. A watt is one joule per second and a kilocalorie or food Calorie is 4,184 joules. The average human requires about 2,500 calories per day.

2,500 Calories $=2,500$ Calories $\times 4,184$ joules $/$ Calorie $=10,460,000$ joules

$10,460,000$ joules $/ 86,400$ seconds per day $=121.06$ joules $/ \mathrm{sec}$ or watts

Each person requires food energy supplied at the constant rate of 121 watts, similar to the energy needed to operate a bright incandescent light bulb.

Human food energy use is small relative to the current average world energy consumption of 2,100 W per person.

$121 \mathrm{~W} / 2,100 \mathrm{~W}=0.057$ or $5.7 \%$

\section{Population limit due to photosynthetic energy for food production}

We will consider different efficiencies for conversion of solar to food energy, with efficiency $E=10^{-4}$ up to $10^{-1}$, from the current to the maximum efficiency. One person's food energy consumption of $121 \mathrm{~W}$ would require $121 / \mathrm{E}$ watts of solar energy.

The total solar incident energy is $1.742 \times 10{ }^{17} \mathrm{~W}$, so the total number of persons fed at efficiency $\mathrm{E}$ is

$\mathrm{N}=1.742 \times 10^{17} \mathrm{~W} /(121 / \mathrm{E}) \mathrm{W}=1.43 \times \mathrm{E} \times 10^{15}$

The efficiency, E, and population, $\mathrm{N}$, are shown in Table 1.

Table 1. Population supported at different food production efficiencies.

\begin{tabular}{|c|c|c|c|c|c|}
\hline \multicolumn{3}{|c|}{} & \multicolumn{3}{c|}{$\begin{array}{c}\text { Years to reach maximum multiple at different } \\
\text { population growth rates }\end{array}$} \\
\hline E, efficiency & N, population & $\begin{array}{c}\text { Multiple of } \\
\text { current } \\
\text { population }\end{array}$ & $2.8 \%$ & $2.2 \%$ & $1.1 \%$ \\
\hline 0.0001 & 143 billion & 20 & 108 & 138 & 274 \\
\hline 0.001 & 1.43 trillion & 204 & 192 & 243 & 484 \\
\hline 0.01 & 14.3 trillion & 2,043 & 275 & 349 & 695 \\
\hline 0.1 & 143 trillion & 20,429 & 359 & 455 & 905 \\
\hline
\end{tabular}

The current world population is about 7 billion. With the current admittedly wasteful food efficiency of $\mathrm{E}=$ 0.0001 , the current population could multiply only twenty times before being limited by the maximum food that can be produced from solar energy. Suppose food technology reaches its theoretical limit. With the theoretical maximum efficiency of solar energy conversion at approximately $10 \%$, and nearly all of this consumed food, the maximum food efficiency would be $\mathrm{E}=0.1$, and the current population could multiply twenty thousand times before being limited by food. 


\section{E. Growth rates and times to reach the maximum population limit}

How long it would take to reach the maximum food limited population in Table 1 depends on the rate of population growth. On the open American frontier, population could double every 25 years, corresponding to an exponential increase of 2.8 percent per year. The world population growth rate has declined from a peak of 2.2 percent in the early 1960 's to 1.1 percent recently. ${ }^{8}$ The limiters have long predicted declining population growth rates, but they thought it would be due to the limitation of resources. Current global living standards are increasing significantly.

The number of years required to reach the maximum population for different food production efficiencies is given in Table 1 for different food production efficiencies and different population growth rates. At the current low food efficiency, $\mathrm{E}=0.0001$, and the maximum frontier population growth rate, $2,8 \%$, the maximum population of 143 billion would be reached in only 108 years. At the maximum possible food efficiency, $\mathrm{E}=0.1$, and the recent low population growth rate, $1.1 \%$, the maximum population of 143 trillion would be reached in only 905 years.

Clearly Malthus and the limiters are right. Exponential growth cannot continue indefinitely on the planet Earth. This poses a challenge to our current high growth industrial and technical world economy.

\section{Expanding into the solar system}

If the economy and population of Earth become restricted because the solar power incident on Earth is fully used, it would be possible to collect solar power in space and transmit it to a collector on Earth using microwaves or lasers. Space based solar power systems were suggested by Asimov in the 1940's and have been studied by NASA since the 1970's. Currently solar power from space would be many thousands of times more expensive than terrestrial solar power, and it will always be significantly more expensive. ${ }^{9}$ Reducing the cost and implementing the technology for space based solar power is the most direct way to escape the limit to future exponential growth that is defined by the total solar power incident on Earth. If we want to escape the limits to growth on Earth, we must escape Earth.

\section{A. Solar power available}

How much solar power is available in near space? Table 2 shows the solar power received on Earth and by circular areas with the radius of geosynchronous orbit or the Moon's orbit, if these areas were oriented perpendicular to the sun's light.

Table 2. Solar power and population growth in space.

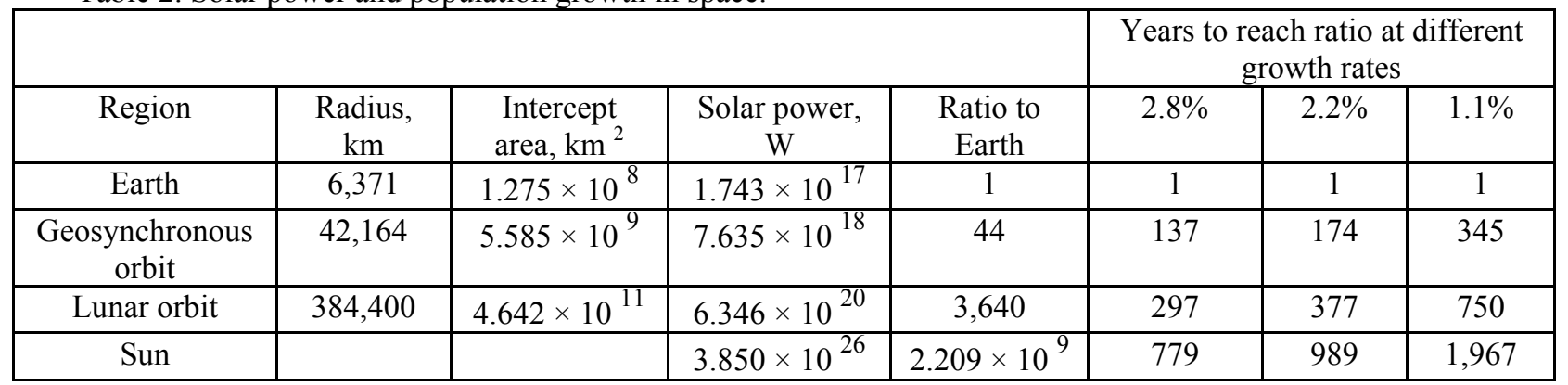

Geosynchronous orbit has 44 times greater sun facing area and incident solar power than the Earth. Lunar orbit has 3,640 times the area and solar power than the Earth. The entire energy output of the sun is about 2 billion times the energy received on Earth. ${ }^{10}$ Directing increasing amounts of energy to Earth will increase global warming. The Earth's average temperature is maintained by the balance of solar energy input during the day and the radiation of heat to the cold dark sky at night. The amount of energy that can be sent to Earth would be limited by the technology developed to radiate heat to space.

Continuing to increase the human population and energy consumption would require transferring and expanding population and energy use off Earth. Freeman Dyson in 1960 suggested that human and possibly alien technical civilizations would continually increase their power consumption and would ultimately use the entire energy output of their star. A swarm of orbiting collectors and space habitats would obscure the star and radiate heat. The Dyson sphere concept was first mentioned by Stapledon in the 1930's. ${ }^{11}$ 
Assuming that energy is used in the Dyson sphere with the same efficiency as it was on Earth before beginning the human expansion into space, the Dyson sphere could support 2 billion times the original population of Earth. If the initial Earth population was one trillion, the 2 billion expansion factor would mean that each 500 people originally on Earth would expand to populate the equivalent of another Earth. Nevertheless, exponential growth will relatively rapidly fill the Dyson sphere and consume all available solar energy. At an open frontier expansion rate of $2.8 \%$, this would require only 779 years, and at the current $1.1 \%$ world growth rate, only 1,967 years.

\section{B. Expanding into near Earth space and the solar system}

Now and for five decades near Earth space has been filled with communications, weather, and Earth observing satellites with commercial and military uses. The highest purpose of the nation state is maintaining its security, which requires military and commercial strength. National security now depends significantly on the control and protection of space assets. The emergence of a geopolitical rival to the United States would probably trigger a renewed more defense oriented space race. This would lead to the development of a technological infrastructure and increased human presence in near Earth space. Solar power transmission, space manufacturing, and asteroid mining would follow.

Space habitats could exploit the space, materials, and solar energy first in the Earth-moon system and later throughout the solar system. They would be supported by robot mining, manufacturing, construction, habitat operation, and long distance transportation. Just as humans are supported on Earth by a natural ecosystem that is based on solar energy and largely empty of humans, humans would be supported in the solar system by a dispersed artificial robot ecosystem.

Expanding into the solar system would escape Earth's limits on solar power and available space, but face a near total lack of material resources. Metals, rocky material, water, and gases would have to be gathered from asteroids, moons, and planets and used to construct human habitats and robot support structures.

The solar system is more likely to be settled by competitive expansionist groups than by a single nation. Ultimately even a Dyson sphere would become crowded. The only way to continue exponential growth would be to expand to the stars.

\section{Colonizing the stars}

Humans seem to be the only technical civilization in the galaxy. We should be able to colonize the stars using currently feasible technology.

\section{A. We are apparently alone in the galaxy}

In considering the possibility of extraterrestrial intelligence, it is often assumed that life will originate on many planets throughout the galaxy, that some life will acquire intelligence, and that some intelligent civilizations will achieve interstellar travel. This scenario was challenged by the physicist Enrico Fermi when he asked, "Where are they?" He reasoned that if there actually were many technical civilizations with interstellar travel, Earth would have been visited many times in the past and probably colonized. ${ }^{12}$ This Fermi paradox implies that we are alone the galaxy.

It is easy to show that a technical civilization with interstellar travel would quickly fill the galaxy. Nuclear propulsion systems using current or near future technology seem capable of rocket exhaust speeds of 0.01 to $0.1 \mathrm{c}$, where $\mathrm{c}$ is the speed of light. The final rocket velocities could be several times higher. Suppose it is possible to travel between the stars at $0.1 \mathrm{c}$. If there were no delay between arriving at a suitable planet and sending out further colonizing expeditions, the frontier of interstellar settlement would expand at $0.1 \mathrm{c}$, the space ship speed. The galaxy could be settled to the far end 100,000 light years distant in about 1 million years. At a ten times slower ship speed of $0.01 \mathrm{c}$, the time to fill the galaxy would be 10 million years. For star systems 10 light years apart, each voyage at $0.01 \mathrm{c}$ would require 1,000 years. Allowing 500 years for planetary settlement and exponential population and economic growth before the next colonizing expedition, the time to fill the galaxy would grow to 15 million years. The universe is roughly 15 billion years old. The time required to colonize the galaxy is only one one-thousandth of its age.

\section{B. How could humans colonize the stars?}

The nearest star system that might have habitable planets is Alpha Centauri at 4.3 light years distance. However, it is a triple star and so is less likely to have planets than a single star. There are only ten stars within 9 light years, and only three of these are single stars. However, there are 55 stars within 16 light years, including 31 single stars. ${ }^{13}$ 
The first human interstellar colonization voyages will probably travel about 10 light years. The time for a starship to travel 10 light years is 100 years at $0.10 \mathrm{c}$ and 1,000 years at $0.01 \mathrm{c}$.

Generations of humans would live out their lives during the long journey. A large multigeneration starship must be developed, equipped, and accelerated to a small fraction of light speed. It is usually assumed that starship food will be grown by hydroponics, but dehydrated food with oxygen and water recycling as on the current space station may require less equipment. The mission cost depends on the size of the crew, the amount of habitat, life support, and colonizing equipment for each crewmember, and the cost per kilogram to accelerate all this equipment mass to its final velocity. Cost is reduced if a small crew travels slowly and lands with minimum equipment. Much of the starship equipment used on the voyage would not be needed to colonize the new star system. To save propulsion mass and cost, only a small part of the starship would decelerate into orbit around the planet. Small descent vehicles would detach from the orbiting spacecraft and land. Many smaller longer colonizing voyages to many different destinations would fill the galaxy sooner than a few larger shorter missions. ${ }^{14}$

It is usually assumed that future civilization on Earth will seek out and colonize Earth-like habitable planets. But if humans first expand into the solar system and establish a Dyson sphere civilization, they could then thrive in any galactic star system. There would be no need to discover habitable planets or provide planetary descent vehicles. There would be no need to terraform new planets or to disturb life on them. And the habitats and factories of a circum stellar civilization could form the basis of a multigeneration starship. A Dyson sphere civilization could colonize all the stars and would spread more rapidly than a planetary civilization.

\section{To continue exponential growth, humans must colonize the stars}

When all the power of the sun is used by a Dyson sphere civilization, a hard limit to exponential growth is reached. The only way to continue the exponential growth of the human population is to colonize the galaxy. The possibility that continued growth may quickly exhaust the Earth's and even the solar system's resources and lead to a collapse of technological civilization suggests that humanity should now begin to plan interstellar robotic exploration and colonization.

If our civilization remains confined to Earth, very many humans will still have worthwhile lives in the future. Even if interstellar travel is developed, only a few humans will ever travel between the stars. But failing to colonize the stars will cause the loss of many trillions of potential future lives, the loss of alternate human cultures and histories on other planets, the loss of interaction and communication between separated and diverging human civilizations. ${ }^{15}$ The growth of science and technology, of literature and art, directly depends on the number of active participants. Progress would be vastly accelerated in an interstellar civilization. The exponential growth of humanity would continue to be exceeded by a greater exponential growth of science and technology, as has occurred in recent centuries.

\section{Conclusion}

Current opinion is divided between those who see inevitable early limits to growth and others who expect long continuing innovation and unrestrained expansion. Confined to finite space but allowed infinite time, the human population and economy must reach an inescapable limit. Continued exponential growth must cease if humanity is confined to Earth. For exponential growth to continue, the human population and economy must expand into space.

\section{References}

${ }^{1}$ Wikipedia, Malthus, http://en.wikipedia.org/wiki/Thomas_Robert_Malthus [accessed June 4, 2014]

${ }^{2}$ Wikipedia, Limits to Growth, http://en.wikipedia.org/wiki/The_Limits_to_Growth [accessed June 9, 2014]

${ }^{3}$ Meadows, D. H., Meadows, D. I., Randers, J., and Behrens, W. W., III , A Report to The Club of Rome (1972), Short Version of 'The Limits to Growth', available at http://www.bibliotecapleyades.net/sociopolitica/esp_sociopol_clubrome6.htm [accessed June 9, 2014]

${ }^{4}$ Turner, G., (2008). "A Comparison of `The Limits to Growth` with Thirty Years of Reality" cited in Wikipedia, Limits to Growth, http://en.wikipedia.org/wiki/The_Limits_to_Growth [accessed June 9, 2014], and in Straus, M, "Looking Back on the Limits of Growth," Smithsonian Magazine, April 2012, http://www.smithsonianmag.com/science-nature/looking-back-on-thelimits-of-growth-125269840/?no-ist [accessed June 9, 2014].

${ }^{5}$ Solow, R., Newsweek, March 13, 1972, page 103, cited in Wikipedia, Limits to Growth, http://en.wikipedia.org/wiki/The_Limits_to_Growth [accessed June 9, 2014],

${ }^{6}$ Abbott, D., “Is Nuclear Power Globally Scalable?” Proceedings of the IEEE, Vol. 99, No. 10, October 2011.

${ }^{7}$ Wikipedia, photosynthetic efficiency http://en.wikipedia.org/wiki/Photosynthetic_efficiency [accessed June 9, 2014]

${ }^{8}$ Wikipedia, Human population growth rate,

http://en.wikipedia.org/wiki/Population_growth\#Human_population_growth_rate, [accessed June 10, 2014]

${ }^{9}$ Wikipedia, Space-based solar power, http://en.wikipedia.org/wiki/Space-based_solar_power, [accessed June 11, 2014] 
${ }^{10}$ Wikipedia, Solar luminosity, http://en.wikipedia.org/wiki/Solar_luminosity [accessed June 11, 2014]

${ }^{11}$ Wikipedia, Dyson sphere, http://en.wikipedia.org/wiki/Dyson_sphere [accessed June 11, 2014]

${ }^{12}$ Webb, S., Where is Everybody? Praxis, New York, 2002.

${ }^{13}$ Kraus, J. D., Radio Astronomy, Cygnus-Quasar, Powell, Ohio, 1986.

${ }^{14}$ Jones, H., "Starship Life Support," 39th International Conference on Environmental Systems, SAE 2009-01-2466. 2009.

15 Jones, H., "Technical Civilizations in the Galaxy" 36th International Conference on Environmental Systems, SAE 200601-2005, 2005. 